\title{
A Psicologia e as Demandas Atuais do Direito de Família
}

Psychology and Some Current Issues in Family Law

La Psicología y las Demandas Actuales del Derecho de Familia

Vivian de Medeiros Lago \& Denise Ruschel Bandeira

Universidade Federal do Rio Grande do Sul 
Resumo: A interdisciplinaridade entre Psicologia e Direito exige uma busca de conhecimentos muitas vezes não adquiridos ao longo da formação acadêmica dos psicólogos. Dentre esses conhecimentos, foram selecionados três tópicos para serem discutidos no presente artigo: guarda compartilhada, síndrome de alienação parental e falsas alegações de abuso sexual. Objetiva-se apresentar uma revisão teórica desses assuntos, abordando aspectos conceituais e históricos. Além da revisão teórica, são apresentados os resultados de uma pesquisa que investigou a formação extracurricular, o conhecimento e a opinião de psicólogos com experiência na área do Direito de família a respeito desses assuntos emergentes. Os resultados revelaram que a maioria dos participantes conhece e tem experiência nas demandas questionadas. Ainda assim, a discussão dos resultados apontou a necessidade de abordar esses e outros assuntos referentes à Psicologia jurídica durante a formação em Psicologia. Os resultados reforçam a importância de o psicólogo jurídico estar familiarizado com questões do Direito de família e considerar em sua avaliação os vínculos afetivos saudáveis ao desenvolvimento da criança.

Palavras-chave: Psicologia jurídica. Guarda compartilhada. Síndrome de Alienação Parental. Abuso sexual.

\begin{abstract}
The interdisciplinary aspect between psychology and law requires psychologists to search for knowledge which has not been acquired during college education. Therefore, three topics were chosen to be discussed in this paper: joint custody, parental alienation syndrome and false allegations of sexual abuse. The article aims to present a theoretical review about these topics, in which their concepts and historical aspects are discussed. Besides the theoretical review, this work presents the results of a research that investigated extracurricular education, knowledge and the opinion on family law of experienced psychologists about these emerging topics. Findings indicated that most of the participants know about and have experience in the demands required. Even though, the discussion of the results pointed out the need of dealing with these and other topics related to forensic psychology during psychologists' education. Lastly, it is highlighted the importance for the psychologist to get familiar with questions of family law, in order to consider in his/her psychological assessment the emotional bonds which are healthier for the children's development.
\end{abstract}

Keywords: Forensic psychology. Joint custody. Parental Alienation Syndrome. Sexual abuse.

Resumen: La interdisciplinaridad entre Psicología y Derecho exige una búsqueda de conocimientos muchas veces no adquiridos a lo largo de la formación académica de los psicólogos. Entre esos conocimientos, fueron seleccionados tres tópicos para ser discutidos en el presente artículo: guarda compartida, síndrome de alienación parental y falsas alegaciones de abuso sexual. Se tiene como objetivo presentar una revisión teórica de estos asuntos, abordando aspectos conceptuales e históricos. Además de la revisión teórica, son presentados los resultados de una pesquisa que investigó la formación extracurricular, el conocimiento y la opinión de psicólogos con experiencia en el área del Derecho de familia a respeto de estos asuntos emergentes. Los resultados revelaron que la mayoría de los participantes conoce y tiene experiencia en las demandas cuestionadas. Aún así, la discusión de los resultados señaló la necesidad de abordar ésos y otros asuntos referentes a la Psicología jurídica durante la formación en Psicología. Los resultados refuerzan la importancia del psicólogo jurídico de estar familiarizado con cuestiones del Derecho de familia y considerar en su evaluación los vínculos afectivos saludables al desarrollo del niño.

Palabras clave: Psicología jurídica. Guarda compartida. Síndrome de Alienación Parental. Abuso sexual.

A interdisciplinaridade entre a Psicologia e o Direito torna necessário o conhecimento de terminologias e procedimentos jurídicos. Tal necessidade conduz a um questionamento acerca de onde e como buscar esses conhecimentos. Através de uma análise dos currículos dos principais cursos de graduação em Psicologia no Brasil, foi possível evidenciar que não são todos os cursos que oferecem a disciplina Psicologia jurídica. E, quando o fazem, normalmente é uma matéria opcional e com uma carga horária reduzida. A formação acadêmica voltada para a área clínica gera profissionais pouco preparados para atuar no âmbito forense, onde é necessário atentar a muitas especificidades e à relevância dos documentos, que podem ter conseqüências legais. Assim, é preciso buscar cursos de especialização ou de capacitação (quando há oferecimento dos mesmos) ou então valer-se de leituras e supervisões, procurando garantir a qualidade do trabalho.

A crescente ascensão da Psicologia jurídica no Brasil (Jacó-Vilela, 1999) e as deficiências encontradas na formação acadêmica, 
observadas na prática docente e clínica das autoras, levam à reflexão sobre assuntos emergentes na área de interface entre a Psicologia e o Direito de família. Essa é uma área em expansão, que exige a atualização dos profissionais que nela atuam. Foram selecionados, assim, três assuntos considerados demandas atuais no Direito de família: guarda compartilhada, Síndrome de Alienação Parental (SAP) e falsas alegações de abuso sexual para serem discutidos no presente trabalho.

Tendo em vista a carência de estudos empíricos e de revisões de literatura sobre as temáticas acima citadas, o presente artigo tem dois propósitos. O primeiro objetivo é apresentar uma revisão teórica mais aprofundada sobre os temas acima referidos, visando a esclarecer questões históricas e conceituais, além das repercussões dos mesmos nas famílias envolvidas numa disputa de guarda. O segundo objetivo é apresentar os resultados de um estudo que investigou a necessidade de formação extracurricular e o conhecimento, a experiência e a opinião de psicólogos que atuam em casos de disputa de guarda sobre os assuntos considerados emergentes no Direito de família.

\section{Guarda compartilhada}

Nos processos de separação ou divórcio, é preciso definir qual dos ex-cônjuges deterá a guarda dos filhos. Conforme o artigo no 1.584, do Novo Código Civil, vigente desde janeiro de 2002, nos casos de separação consensual, será observado o que os cônjuges acordarem sobre a guarda dos filhos. Em não havendo acordo, a guarda será atribuída àquele que reunir melhores condições para exercê-la, o que não implica melhores condições econômicas ou materiais (Brasil, 2003).

A guarda poderá ser exclusiva ou compartilhada. De acordo com Trindade (2004), a guarda exclusiva ou simples é aquela em que ambos os genitores mantêm o poder familiar, mas as decisões recaem sobre o pai guardião. $\mathrm{Na}$ guarda compartilhada, ambos os pais detêm o poder familiar e a tomada de decisões, independentemente do tempo em que os filhos passem com cada um deles. A guarda exclusiva ainda é predominante no Brasil, ficando os filhos normalmente sob a custódia da mãe. De acordo com dados do Instituto Brasileiro de Geografia e Estatística (IBGE, 2005), em 91,1\% dos casos de separação e em $89,5 \%$ dos casos de divórcio, a guarda dos filhos ficou sob responsabilidade da mãe.

Contudo, em junho de 2008, foi sancionado pelo Presidente da República o projeto de lei que prevê a inclusão da guarda compartilhada na legislação brasileira. O Projeto de Lei no 6.350/2002, de autoria do Deputado Tilden Santiago, define a guarda compartilhada e estabelece os casos em que a mesma será possível, ressaltando que a guarda poderá ser modificada a qualquer momento, atendendo ao melhor interesse da criança (Brasil, n.d.).

Antes de discutir o instituto da guarda compartilhada, é importante buscar suas origens. Peres (2002) relata que a Inglaterra é pioneira nesse sistema, tendo o primeiro caso sido julgado ainda na década de 1960. O sistema inglês da commom law objetivou romper a tendência de deferir a guarda exclusiva para a figura materna, visando ao compartilhamento dos direitos e das obrigações com os filhos entre os genitores. Em 1976, o instituto foi assimilado pelo Direito francês, com o propósito de amenizar os prejuízos que a guarda exclusiva acarreta aos filhos de pais separados. Após essa trajetória na Europa, a guarda compartilhada difundiu-se na América do Norte. Bauserman (2002) destaca que os Estados Unidos foi o país em que o instituto ganhou maior adesão e desenvolvimento. Nesse país, a guarda compartilhada é conhecida como joint custody ou shared parenting, e divide-se 
Lima (2007) observa que é freqüente 0 abandono do pai, após a separação conjugal, do acompanhamento cotidiano dos

filhos e de suas atividades escolares. Isso pode implicar um fracasso escolar das crianças, denunciando a gravidade da ausência de um dos pais na estruturação psíquica dos filhos. em guarda compartilhada jurídica e guarda compartilhada física. Na primeira, é feita apenas a divisão dos direitos e deveres, enquanto na segunda, além dessa divisão, há também a divisão de domicílio.

Essa classificação existente nos Estados Unidos traz confusão para o conceito de guarda compartilhada que vem sendo utilizado no Brasil, pois muitos profissionais posicionam-se contrariamente a esse instituto por entenderem que a alternância de lares é prejudicial ao desenvolvimento das crianças. Contudo, é preciso atentar para as diferenças entre guarda alternada e guarda compartilhada. A primeira implica a possibilidade de cada um dos pais deter a guarda do filho alternadamente, com divisões de tempo que podem variar de dias a anos alternados. A guarda compartilhada não implica alternância de lares, e sim uma co-responsabilização de dever familiar entre os pais.

Cabe observar que o sistema da guarda compartilhada não é aplicável a todos os casos de separação conjugal. Saposnek (1991) discute a decisão da guarda compartilhada, enfocando as necessidades dos filhos do divórcio. O referido autor destaca que definir se a guarda compartilhada funciona ou não é uma tarefa muito complexa. É preciso analisar a história do casal, as disputas pré e pós-divórcio, a idade dos filhos, os estilos de temperamento, a qualidade dos relacionamentos pais-filhos, as habilidades de coping e o exercício da co-parentalidade. Esse conjunto de aspectos é que será determinante para o sucesso ou fracasso da guarda compartilhada.

Irving e Benjamin (1991) realizaram um estudo comparativo no Canadá, com 201 pais com guarda compartilhada e 194 mães com guarda exclusiva. Os resultados revelaram que, na maioria dos casos, a guarda compartilhada ofereceu um sistema de guarda satisfatório para pais e filhos. Com o decorrer do tempo, os ajustes e a convivência entre pais e filhos sob esse sistema apresentaram melhoras. A escolha pela guarda compartilhada pareceu indicada nos casos de casais com os seguintes atributos: (a) baixos níveis de conflitos anteriores à separação; (b) um exercício da paternidade/maternidade centrado na criança; (c) concordância em relação à decisão do término da relação conjugal e à decisão da guarda compartilhada e (d) motivação de ambos os pais para aceitar e superar as exigências e complicações do dia a dia invariavelmente associadas ao exercício da guarda compartilhada.

Lima (2007) observa que é freqüente o abandono do pai, após a separação conjugal, do acompanhamento cotidiano dos filhos e de suas atividades escolares. Isso pode implicar um fracasso escolar das crianças, denunciando a gravidade da ausência de um dos pais na estruturação psíquica dos filhos. Considerando as conseqüências da separação do filho de um de seus genitores, Silva (2005) aponta a importância de manter os vínculos positivos dos filhos com ambos os pais, nem sempre sendo necessário confiar a apenas um dos dois a continuidade da tarefa de cuidá-los. É importante que a criança conviva com ambos os pais, para que construa uma relação e forme por si mesma uma imagem de cada um de seus genitores. Quando não é possibilitada uma convivência mais assídua com um dos genitores, normalmente a imagem do progenitor que não detém a guarda é formada com a interferência daquele que a detém, influenciada muitas vezes por sentimentos de rancor e desavenças conjugais existentes.

Esses sentimentos de rancor e amargura podem trazer sérias conseqüências para o desenvolvimento das crianças, principalmente quando as mesmas são afastadas do convívio do genitor não-guardião. Atualmente, esse fenômeno tem sido evidenciado com mais 
freqüência entre casais que se separam (Gardner, 1999) e, portanto, será o próximo assunto discutido neste artigo.

\section{Síndrome de alienação parental}

O fenômeno da Síndrome de Alienação Parental (SAP) tem sido comumente visto no contexto de disputas de guarda (Gardner, 1999). O assunto é recente na literatura brasileira e é desconhecido por parte dos profissionais que trabalham com o Direito de família. É necessário que os psicólogos conheçam a SAP, a fim de identificar suas características em um processo de disputa judicial e de intervir de forma a amenizar as conseqüências da mesma.

O termo síndrome de alienação parental foi criado pelo psiquiatra norte-americano Richard Gardner. O referido autor observou um aumento significativo das situações em que um dos genitores programa o filho para alienar-se do outro, na esperança de que isso o favoreça na disputa judicial. A partir daí, Gardner (2002) constatou não apenas que o genitor alienador incutia no filho idéias negativas em relação ao ex-cônjuge, mas que havia também uma contribuição dos filhos para essa desmoralização.

Gardner (2002) definiu então a SAP como o processo que consiste em programar uma criança para que odeie um de seus genitores sem justificativa. O termo "programar" não é bem aceito por muitos profissionais, que o consideram uma terminologia muito forte. Contudo, Gardner explica as razões de sua escolha pelo vocábulo. A definição encontrada pelo autor no dicionário refere-se ao verbo programar como "causar absorção ou incorporar respostas ou atitudes automáticas" (Gardner, 2002, p. 94). No dicionário da língua portuguesa Aurélio, encontramos uma definição apropriada para essa situação, em que programar é sinônimo de "determinar a forma de funcionamento". Assim, o termo "programar" aplica-se ao conceito da SAP para definir a implantação de informações que estejam diretamente em discordância com o que a criança experimentou previamente com o genitor alienado.

Para que se configure efetivamente o quadro da SAP, Silva (2006) destaca que é preciso ter certeza de que o genitor alienado não merece ser rejeitado pela criança por meio de comportamentos tão depreciáveis. Gardner (2002) aponta ainda que a SAP se caracteriza pelo fato de o alienador programar o filho para denegrir a imagem do outro genitor e pelas contribuições criadas pela própria criança, que sustentam essa desmoralização do genitor alienado. Sem essa contribuição da criança, não é possível falar em SAP, pois a mesma só se estabelece mediante a complementaridade entre destruição da imagem pelo genitor e pelo próprio filho, ainda que influenciado pelo primeiro.

O alienador caracteriza-se como uma figura superprotetora, que pode ficar cego de raiva ou animar-se por um espírito de vingança provocado pela inveja ou pela cólera. Geralmente, coloca-se como vítima de um tratamento injusto e cruel por parte do outro genitor, do qual tenta vingar-se fazendo crer aos filhos que aquele não é merecedor de nenhum afeto. Dias (2006) observa que o detentor da guarda, ao destruir a relação do filho com o outro, assume o controle total, unindo-se ao filho. O pai não-guardião passa a ser considerado um invasor, um intruso a ser afastado a qualquer preço. Esse conjunto de manobras confere prazer ao alienador em sua trajetória de promover a destruição do antigo parceiro. Seu objetivo é distanciar o filho do outro genitor (Simão, 2007) por meio de interceptação de ligações e de correspondências e pelo uso de termos pejorativos e críticas ostensivas ao estilo de vida. Dessa forma, conforme observa Silva (2006), o filho absorve essa negatividade em relação ao genitor alienado, sentindo-se 
no "dever" de proteger o alienador. Assim, estabelece-se um pacto de lealdade em função da dependência emocional e material, que faz com que o filho demonstre medo em desagradar ou em opor-se ao genitor guardião.

O termo "síndrome" é utilizado porque Gardner (1999) observou um conjunto de sintomas que costumam aparecer nas crianças vítimas desse processo, os quais variam de um nível moderado a grave. São eles: (1) campanha de descrédito (manifestada verbalmente e nas atitudes); (2) justificativas fúteis (o filho dá pretextos fúteis para justificar a atitude); (3) ausência de ambivalência (o sentimento do filho pelo genitor alienado é inequívoco: é o ódio); (4) fenômeno de independência (o filho afirma que ninguém o influenciou); (5) sustentação deliberada (o filho adota a defesa do genitor alienador); (6) ausência de culpa sobre a crueldade do genitor alienado (o filho não sente culpa por denegrir o genitor alienado); (7) presença de situações fingidas (o filho conta casos que manifestadamente não viveu); (8) generalização de animosidade em relação a outros membros da família extensiva do genitor alienado (Major, 2000).

Ao observar todos os sintomas que a SAP pode produzir nas crianças, é importante apontar o fato de que um genitor que incute tais idéias no filho está causando-lhe um abuso emocional. Conforme Gardner (2002), o genitor que programa seu filho de forma a rejeitar um pai amoroso e devotado, privando-o da participação na educação de seu filho, causa a destruição total e muitas vezes irremediável desse vínculo. O genitor alienado, que a criança aprende a odiar por influência do genitor alienador, passa a ser um estranho para ela. Dessa forma, o genitor alienador configura-se como modelo prejudicial à criança, em razão de seu caráter patológico e mal-adaptado. De acordo com Silva (2006), a criança tenta reproduzir a mesma patologia psicológica que o genitor alienador. A SAP pode gerar efeitos em suas vítimas, como: depressão crônica, incapacidade de adaptação social, transtornos de identidade e de imagem, desespero, sentimento de isolamento, comportamento hostil, falta de organização, tendência ao uso de álcool e drogas quando adultas e, às vezes, suicídio. Podem também ocorrer sentimentos incontroláveis de culpa quando a criança se torna adulta e percebe que foi cúmplice inconsciente de uma grande injustiça quanto ao genitor alienado.

Para o diagnóstico da síndrome de alienação parental, Gardner (2002) ressalta a importância de realizar entrevistas conjuntas, com todas as partes envolvidas e em todas as combinações possíveis. É durante as entrevistas conjuntas que o examinador tem a possibilidade de confrontar as informações e investigar a verdade. Conforme observa Motta (2007), o relacionamento entre a criança e o genitor acusado é diminuído e quase sempre interrompido durante as investigações para a realização de perícia, que podem durar meses ou anos na tentativa de se atingir um nível de certeza considerável. Assim, além de diagnosticar a SAP, é importante que os psicólogos busquem formas de intervenção que possam amenizar os efeitos causados por esse fenômeno. É preciso tratar a psicopatologia do genitor alienador, visivelmente prejudicado em razão de suas atitudes para com o filho. O mais complexo no tratamento da SAP é a busca pela reconstrução do vínculo entre filho e genitor alienado e a redução dos danos causados em razão do rompimento desse vínculo. Podem acontecer situações em que, concomitante ou paralelamente ao processo de disputa de guarda, existam acusações de abuso sexual contra um dos genitores envolvidos na disputa judicial.

\section{Falsas acusações de abuso sexual}

O que se pretende nesta seção do artigo é chamar a atenção dos profissionais que 
trabalham com disputa de guarda para a possibilidade de as acusações de abuso sexual serem falsas, em função de sentimentos de vingança ou desavenças entre os ex-cônjuges. É sabido que situações de abuso sexual intrafamiliar são freqüentes e apresentam conseqüências danosas às vítimas (Flores \& Caminha, 1994). De acordo com Kaplan e Sadock (1990), aproximadamente 50\% do abuso é cometido por membros da família. Contudo, o foco aqui apresentado será nas alegações de abuso sexual que envolvem a disputa de guarda, o que exige do psicólogo uma postura mais crítica sobre o assunto.

Apesar de não citar pesquisas, Gardner (1987) acredita que 95\% dos casos de acusações de abuso sexual no contexto de disputa de guarda sejam falsos. Esse percentual é muito alto, o que demanda cuidados por parte do profissional a quem é solicitada a avaliação do abuso. Conforme ressalta Deed (1991), é importante compreender o papel que o abuso sexual infantil pode estar desempenhando nas famílias em processo de divórcio.

A avaliação de acusações de abuso sexual em casos de disputa de guarda é uma tarefa complexa. Primeiramente, uma variedade de dinâmicas familiares está presente em tais acusações. De acordo com Bow, Quinnell, Zaroff e Assemany (2002), os motivos das partes para tais alegações podem variar desde uma necessidade de proteção à segurança do filho até sentimentos de vingança e hostilidade após a separação conjugal. Assim, o avaliador deve explorar e compreender o sistema familiar e a validade das queixas apresentadas. Há que se considerar ainda que, em contraste com os casos de abuso extrafamiliar, nos casos de disputa de guarda, o suspeito é comumente uma das partes envolvidas no processo judicial.

McGleughlin, Meyer e Baker (1999) apontam a dificuldade em distinguir entre os sintomas apresentados por crianças com conflitos decorrentes da situação de divórcio e crianças que foram abusadas sexualmente, uma vez que há muita sobreposição entre os tipos de sintomas apresentados por essas crianças. Bow et al. (2002) consideram que o psicólogo que atua nessa área deve possuir conhecimentos de três áreas forenses: as práticas e procedimentos em disputa de guarda, as técnicas de avaliação de abuso sexual e a avaliação dos supostos abusadores.

Calçada (2005) observa que não se deve iniciar uma avaliação de abuso sexual considerando que a denúncia seja válida. A atitude deve ser de respeito e de busca de evidências. É necessário investigar o entorno histórico e social da família, jamais levando em consideração apenas o relato da criança, o que pode nos levar ao erro de entrar na sua fantasia. Há que se atentar também para o fenômeno da negação, que é um perfil não só dos abusadores mas também dos falsos acusados. O acusado fornecerá informações e documentos importantes, que devem ser checados e, se necessário, incluídos na investigação. Myers (1992) ressalta que a entrevista com a vítima também é muito complicada por inúmeros fatores, como memória, sugestionabilidade, habilidade para distinguir entre realidade e fantasia e a veracidade das afirmações. Calçada, Cavaggioni e Neri (2001) sugerem que a entrevista seja conduzida de maneira que a criança se sinta livre o suficiente para relatar o que desejar, ou seja, não há uma história a ser contada. É importante acessar a memória, e não aquilo que foi instruído ou ouvido repetidamente. Perguntas diretivas do avaliador podem ocasionar sugestionabilidade da criança e talvez prejudicá-la permanentemente.

Uma pesquisa realizada por Bow et al. (2002) nos Estados Unidos investigou acusações de abuso sexual em avaliações que envolvem a disputa de guarda. Os resultados indicaram 
De acordo com Stein (2000), as falsas memórias têm assumido um papel muito importante nessa área da Psicologia do testemunho. Várias pesquisas vêm sendo

desenvolvidas na área, a fim de contribuir para a elucidação dos mecanismos responsáveis pelas falsas memórias e, portanto, de auxiliar 0 aprimoramento de técnicas para avaliação de testemunhos

(Nygaard, Feix, \& Stein, 2006; Pisa \& Stein, 2006; Stein \& Nygaard, 2003; Tonetto, Kalil, Melo, \& Schneider, 2006). que, em $60 \%$ dos casos, as alegações de abuso precederam a determinação de guarda, enquanto em $40 \%$ dos casos foi requerida a modificação do arranjo de guarda inicialmente estipulado. O pai biológico foi identificado como o acusado mais freqüente nesses tipos de avaliação (55\%), seguido pelo padrasto $(25 \%)$, pela mãe biológica $(11 \%)$, por outros familiares ou conhecidos (11\%), pelos irmãos (9\%) e pela madrasta (4\%). A maioria das vítimas tinha menos de 10 anos, sendo que $52 \%$ tinha menos de sete anos. Em média, os participantes relataram a confirmação das acusações de abuso em cerca de $30 \%$ dos casos de disputa de guarda. Esses dados corroboram os resultados encontrados por Wakefield e Underwager (1991), mas são inferiores aos obtidos nos estudos de McGraw e Smith (1992), Benedek e Schetky (1985) e Thoennes e Tjaden (1990), que encontraram a confirmação em $44,6 \%$, 45\% e $50 \%$ dos casos, respectivamente.

É importante observar que as falsas acusações de abuso sexual podem ser uma das formas da síndrome de alienação parental, uma vez que se configura como uma tentativa de destruição da figura parental (Calçada, 2005). As conseqüências para as crianças envolvidas nesse processo podem ser semelhantes às de crianças que foram de fato abusadas, e essas podem passar a apresentar algum tipo de patologia grave nas esferas afetiva, psicológica e sexual e, ainda, acreditarem que o abuso realmente ocorreu (Calçada et al., 2001).

Considerando que as crianças, especialmente as vítimas da síndrome de alienação parental, se utilizam de situações descritas que nunca foram efetivamente vivenciadas, é importante que o psicólogo analise os processos da memória que originaram tais lembranças. Rovinski (2004) afirma que o fato de a criança já ter passado por diversas entrevistas até chegar à avaliação psicológica pode fazer com que a mesma traga um relato contaminado com informações que muitas vezes não condizem com a realidade do evento traumático. A partir de informações recebidas, a criança passa a apresentar recordações de eventos que podem não ter de fato ocorrido, ou que não ocorreram da forma como ela recorda, apesar de considerar essas lembranças reais. Trata-se do fenômeno das falsas memórias, estudado pelo ramo da Psicologia cognitiva.

De acordo com Stein (2000), as falsas memórias têm assumido um papel muito importante nessa área da Psicologia do testemunho. Várias pesquisas vêm sendo desenvolvidas na área, a fim de contribuir para a elucidação dos mecanismos responsáveis pelas falsas memórias e, portanto, de auxiliar o aprimoramento de técnicas para avaliação de testemunhos (Nygaard, Feix, \& Stein, 2006; Pisa \& Stein, 2006; Stein \& Nygaard, 2003; Tonetto, Kalil, Melo, \& Schneider, 2006). Dessa forma, observa-se quão amplo é o campo da avaliação de abuso sexual que envolve disputa de guarda, pois abrange conhecimentos das mais diferentes áreas, incluindo o fenômeno das falsas memórias.

A importância de conhecer o assunto das falsas acusações de abuso sexual se reflete na validade dos dados que serão apresentados ao juiz. Uma avaliação imprecisa, com resultados não fidedignos, pode levar o juiz à determinação de visitas supervisionadas ou até mesmo à suspensão das visitas do genitor acusado, além da possível condenação no âmbito criminal. Dessa forma, pode acontecer um aniquilamento da relação pai-filho, e, até que se prove o contrário, muito tempo pode ter se passado e os vínculos afetivos sofrerem um prejuízo irremediável.

A partir de agora, serão apresentados os resultados do estudo empírico realizado com psicólogos com experiência em situações de disputa de guarda. Os profissionais responderam questões relativas à guarda exclusiva para genitores masculinos, ao 
conhecimento e à opinião sobre a guarda compartilhada, ao conhecimento e à experiência sobre síndrome de alienação parental e às falsas acusações de abuso sexual.

\section{Método}

\section{Participantes}

Psicólogos de diferentes Estados do Brasil, com experiência em avaliação psicológica em situações de disputa de guarda, participaram de uma pesquisa de levantamento. Os critérios de inclusão adotados foram: estar devidamente registrado em um dos Conselhos Regionais de Psicologia e ter realizado no mínimo duas avaliações psicológicas que envolvessem disputa de guarda. Um total de 53 profissionais respondeu ao instrumento da pesquisa. Dois participantes foram retirados da amostra por não preencherem os critérios de inclusão e um por não responder à última seção do questionário. Assim, a amostra final contou com 50 psicólogos, cuja média de idade foi de 41,82 anos (DP=10,21).

Dentre os participantes, $88 \%$ eram do sexo feminino, e $12 \%$, do sexo masculino. A distribuição dos respondentes conforme a Região brasileira foi a seguinte: Sudeste (54\%), Sul (28\%), Centro-Oeste (10\%), Nordeste $(6 \%)$ e Norte $(2 \%)$. Em relação à formação acadêmica, 84\% dos participantes informaram que não cursaram nenhuma disciplina de Psicologia jurídica ao longo da graduação, e o mesmo percentual de respondentes relatou possuir curso de pósgraduação. No que diz respeito à vinculação profissional, a maioria dos respondentes (62\%) está vinculada ao Poder Judiciário.

\section{Instrumento}

Os participantes deste estudo responderam a um questionário disponível online, composto por 47 questões, a maioria objetivas. A construção desse instrumento se deu a partir da revisão da literatura e também da análise de conteúdo de entrevistas semi-estruturadas realizadas com quatro psicólogas da cidade de Porto Alegre-RS, com experiência em avaliação relativa a disputa de guarda. As entrevistas foram gravadas e transcritas, e procedeu-se à análise de conteúdo das respostas. A partir das unidades de análise levantadas e da revisão teórica realizada, foram construídas questões objetivas de múltipla escolha, com o propósito de tornar a aplicação do instrumento fácil e rápida. Esse conjunto de perguntas compôs o questionário final, dividido em quatro seções: dados pessoais e profissionais, avaliação psicológica nos casos de disputa de guarda, uso de testes e demandas atuais do Direito de família. Os dados da segunda e terceira seções estão publicados em artigo intitulado "As práticas em avaliação psicológica envolvendo disputa de guarda no Brasil" (Lago \& Bandeira, 2008). No presente artigo, serão apresentados os dados referentes à última seção do questionário, em que os participantes responderam acerca de seu conhecimento, opinião e experiência a respeito da guarda compartilhada, síndrome de alienação parental e das falsas acusações de abuso sexual.

\section{Procedimentos}

Para compor a rede de participantes, foram enviadas correspondências eletrônicas a todos os Conselhos Regionais de Psicologia, visando à divulgação do estudo e à solicitação de indicação de profissionais para compor a amostra. Uma apresentação do estudo, explicando a justificativa e os objetivos da pesquisa, foi enviada em anexo. O baixo retorno de indicações fez com que se buscassem outras alternativas para o recrutamento dos participantes; portanto, foi realizada uma busca no Currículo Lattes, através das palavras-chave "disputa de guarda" e "avaliação psicológica forense", e também foram enviados emails para dois 
grupos de discussão da Internet, um de avaliação psicológica e outro de Psicologia jurídica. Aos psicólogos que entravam em contato com a pesquisadora, ou que respondiam o questionário, foi solicitada a indicação de colegas de trabalho com experiência no assunto. Dessa forma, a amostra composta foi não-probabilística, em sua forma conhecida por snowball, em que um participante podia indicar outro para construir a rede de respondentes. Entretanto, é importante observar que essa forma de procedimento não permitia o controle do número de acessos à página da Internet em que estava o instrumento e, assim, não é possível detectar quantas pessoas acessaram a homepage, mas não aceitaram participar do estudo.

O presente estudo foi encaminhado ao Comitê de Ética em Pesquisa do Instituto de Psicologia da Universidade Federal do Rio Grande do Sul e recebeu aprovação. O Termo de Consentimento Livre e Esclarecido estava disponível na página da Internet indicada aos psicólogos no convite feito para participar do estudo. Os respondentes podiam clicar no botão "aceito" ou "não aceito". Os que clicavam no "não aceito" não tinham acesso ao instrumento. Os que consentiam em participar acessavam então as instruções de preenchimento do questionário. Ao clicar no botão "enviar", as respostas eram encaminhadas para o endereço eletrônico da pesquisadora, através de um formulário eletrônico que preservava o anonimato dos participantes. Os respondentes que desejassem receber antecipadamente uma síntese dos principais resultados do estudo poderiam identificar-se, deixando seu endereço eletrônico para correspondência ao final das respostas. Apenas três participantes não deixaram seu e-mail.

Análise dos dados

Foram realizadas a revisão, a codificação e a digitação dos dados obtidos. Foram feitas análises descritivas das características sociodemográficas e de formação dos participantes da amostra, assim como das questões sobre as demandas atuais do Direito de família contempladas no instrumento.

Em virtude das diversidades regionais existentes no Brasil, foram realizadas comparações dos resultados entre as Regiões, através do Teste do Qui-Quadrado. Devido ao reduzido número de participantes das regiões Norte, Nordeste e Centro-Oeste, optou-se por um agrupamento dessas Regiões a fim de realizar as comparações propostas. Serão apresentadas comparações entre as Regiões brasileiras apenas quando apresentarem diferenças significativas.

\section{Resultados}

Inicialmente, serão apresentados os resultados dos questionamentos feitos aos participantes acerca da necessidade de formação extracurricular na área jurídica. É importante lembrar que apenas $16 \%$ da amostra cursou alguma disciplina relacionada à Psicologia jurídica durante a graduação. Assim sendo, restava saber quais cursos os participantes necessitaram buscar a fim de complementar sua formação para atuar nesse campo.

Quando questionados sobre a necessidade de buscar conhecimentos através de cursos de extensão, aperfeiçoamento ou capacitação para exercer atividades relacionadas ao meio jurídico, em função de falhas na formação acadêmica, 80\% dos respondentes afirmou ter sentido tal necessidade. A seguir, estava à disposição dos participantes um espaço para elencar os três tipos de cursos mais importantes que foram buscados. Foi realizada uma análise das respostas, que foram agrupadas conforme as áreas. Os tópicos mais citados foram: avaliação psicológica e documentos $(45,7 \%)$, abuso sexual e violência doméstica $(17,1 \%)$ e Psicologia da família $(11,4 \%)$. 
Ao serem questionados sobre a necessidade de realização de encontros, congressos e/ou cursos na área de Psicologia jurídica com o propósito de buscar atualização profissional, 92\% afirmou sentir tal necessidade. A seguir, estava à disposição dos participantes um espaço para elencar os três assuntos que mais exigem constante atualização. Foi realizada uma análise das respostas, agrupadas conforme as áreas. A Tabela 1 apresenta as áreas mais citadas, em que os percentuais correspondem ao total de participantes que citou cada área.

Tabela 1. Áreas apontadas como demandas de atualização profissional.

\begin{tabular}{ll}
\hline Áreas & $\mathrm{F}(\%)$ \\
\hline Avaliação psicológica & $25 \%$ \\
Atuação na área de família & $19,4 \%$ \\
Guarda de filhos & $9,7 \%$ \\
Adoção & $8,3 \%$ \\
Mediação & $6,9 \%$ \\
Integração entre Psicologia, serviço social e Direito & $6,9 \%$ \\
Violência doméstica & $5,6 \%$ \\
Infância e juventude & $4,2 \%$ \\
Ética e documentos & $4,2 \%$ \\
Autópsia psicológica & $1,4 \%$ \\
Depoimento sem dano & $1,4 \%$ \\
Drogadição & $1,4 \%$ \\
Intervenção em conflitos & $1,4 \%$ \\
Justiça terapêutica & $1,4 \%$ \\
Preconceito de gênero & $1,4 \%$ \\
Reprodução assistida & $1,4 \%$ \\
\hline
\end{tabular}

Em relação às demandas recentes no Direito de família, primeiramente foi questionado se os participantes concordavam com o fato de que um crescente número de pais (genitores masculinos) tem buscado junto à Justiça a guarda dos filhos. A maioria dos participantes (98\%) concordou com a afirmativa, sendo que, desse percentual, $76 \%$ já teve experiência em casos de pais que pleitearam a guarda dos filhos e $22 \%$ não teve experiência, mas acredita que esse fato esteja relacionado ao crescente número de disputas judiciais.

A seguir, o questionário apresentava o conceito de guarda compartilhada e era solicitado aos participantes que se manifestassem acerca de seu conhecimento sobre o assunto. Todos os participantes afirmaram conhecer o instituto da guarda compartilhada, sendo que $80 \%$ tem experiência no assunto e $20 \%$ não teve até o momento nenhuma experiência profissional relacionada ao tema. Ao serem questionados sobre sua opinião, 64\% mostrou-se favorável à guarda compartilhada, $8 \%$, desfavorável, e $28 \%$ afirmou que não é possível emitir uma opinião sem analisar a situação concreta, devido à alta individualização dos casos.

No questionário, havia um espaço para os participantes emitirem comentários sobre o assunto da guarda compartilhada. Alguns dos comentários deixados revelam a importância dos vínculos parentais no desenvolvimento das crianças: "Acredito que desta forma o vínculo e responsabilidade de ambos os genitores têm maior chance de manutenção" (P21). "Para a criança, quanto mais 
ambos os pais puderem participar na educação do filho e ainda mais puderem tomar decisões unânimes, cuidar da vida da criança e estar presente em todos os momentos importantes de sua vida, tanto mais haverá a possibilidade da criança evoluir com mais tranqüilidade, menor grau de estresse e maior estabilidade emocional" (P40).

Alguns participantes consideraram que a guarda compartilhada só é possível sob algumas condições: "Penso ser possível naqueles casos em que os casais tenham uma boa elaboração da separação, onde os filhos não estejam ocupando o lugar de projeção de mágoas pessoais" (P37). "É necessário que a relação entre o ex-casal esteja bem resolvida e que haja uma boa comunicação entre eles" (P43). "As guardas tanto alternada como compartilhada exigem um elevado patamar de maturidade e saúde mental dos pais, o que é difícil de encontrar nos casos encaminhados para avaliação psicológica" (P41). "A guarda compartilhada só é possível se ambos residirem na mesma cidade, para que possam dividir as tarefas na educação dos filhos e manutenção dos vínculos pai/mãe" (P11).

Foi destacada ainda a questão da separação da conjugalidade, e não da parentalidade: "Os profissionais chamados a intervir devem mediar as relações, levando os pais a compreender que o fim da conjugalidade não deve significar que um deles tenha que abrir mão do exercício da parentalidade" (P42).

Os participantes foram solicitados a avaliar uma lista de fatores para recomendar a guarda compartilhada, conforme o grau de importância, sendo $1=$ pouco necessário, $2=$ importante e 3 =fundamental. A Tabela 2 apresenta os fatores elencados em ordem de importância, conforme as médias dos resultados.

Tabela 2. Fatores importantes para recomendar a guarda compartilhada.

\begin{tabular}{lll}
\hline Fatores para recomendar a guarda compartilhada & Média & DP \\
\hline Flexibilidade dos pais & 2,51 & 0,77 \\
Relacionamento entre os pais & 2,49 & 0,79 \\
Relacionamento da criança com ambos os pais & 2,48 & 0,71 \\
Maturidade dos pais & 2,40 & 0,77 \\
Conforto e cuidado dos pais para com seus filhos & 2,35 & 0,67 \\
Identificação da criança com cada um dos pais & 2,32 & 0,73 \\
Rotina da criança & 2,26 & 0,71 \\
Presença de fatores de personalidade prejudiciais & 2,07 & 0,79 \\
\hline
\end{tabular}

Em relação à síndrome de alienação parental, 77,5\% dos participantes conhecia o termo, enquanto $22,5 \%$ o desconhecia. Dentre os que conheciam essa denominação, $73,7 \%$ tem experiência no assunto, 7,9\% não tem experiência e 18,4\% relaciona o assunto com falsas acusações de abuso sexual.

A respeito da relação entre processos de disputa de guarda e acusações de abuso sexual, $84 \%$ relatou ter experiência no assunto. Ao se realizar comparações entre as Regiões, não se observaram diferenças acerca da guarda compartilhada e da SAP. Contudo, algumas diferenças puderam ser observadas no que diz respeito à experiência sobre as falsas acusações de abuso sexual, conforme demonstra a Tabela 3. 
Tabela 3. Falsas acusações de abuso sexual conforme a Região brasileira.

\begin{tabular}{llll}
\hline Falsas acusações de abuso sexual & $\begin{array}{l}\mathrm{N}, \mathrm{NO} \text { e CO } \\
(\mathrm{N}=9)\end{array}$ & $\begin{array}{l}\text { Sudeste } \\
(\mathrm{N}=27)\end{array}$ & $\begin{array}{l}\text { Sul } \\
(\mathrm{N}=14)\end{array}$ \\
\hline Não tem experiência & $11,1 \%$ & $7,4 \%$ & $35,7 \%$ \\
Tem experiência & $88,9 \%$ & $92,6 \%$ & $64,3 \%$ \\
\hline
\end{tabular}

Ainda que a diferença não tenha sido estatisticamente significativa $\left(X^{2}=5,692 ; p<0,06\right)$, merece destaque o percentual de participantes da Região Sul que não tem experiência com o assunto das falsas acusações de abuso sexual, em contrapartida com o alto percentual de experiência dos participantes das demais Regiões.

\section{Discussão}

No que diz respeito à formação extracurricular, as categorias apontadas pelos participantes revelam uma variedade de assuntos relacionados não apenas à área do Direito de família, mas à Psicologia jurídica como um todo. Vale apontar que o estudo foi realizado com pessoas que concluíram sua graduação há algum tempo e, portanto, os dados não são os da formação curricular atual. Assim sendo, o que pode ser concluído é que a disciplina Psicologia jurídica não foi ministrada à maioria dos participantes, e, em virtude disso, vários são os assuntos que exigiram uma busca por formação complementar. Sugere-se que estudos acerca da formação nessa área possam ser realizados no futuro e os dados possam ser comparados, a fim de se avaliar os reflexos das mudanças curriculares na formação do psicólogo.

Note-se que, tanto na lista dos assuntos de formação extracurricular quanto na de assuntos sugeridos para congressos e cursos, é possível observar que a avaliação psicológica aparece em primeiro lugar. Esse dado corrobora a relevância dessa área, que se apresenta em franco desenvolvimento (Hutz \& Bandeira, 2003).

Ainda em relação à lista de assuntos que os profissionais gostariam de discutir através de cursos e congressos, é possível observar que a mesma é bem mais ampla e extensa do que a de assuntos de conhecimentos que foram buscados no início do exercício de suas atividades. Essa diferença reforça a expansão da Psicologia jurídica, em seus diversos campos de atuação. É importante destacar que o tópico "avaliação psicológica" aparece em primeiro lugar tanto na lista dos assuntos que exigiram formação complementar quanto na lista de áreas que demandam atualização profissional. Na prática do grupo de pesquisa em avaliação psicológica da Universidade Federal do Rio Grande do Sul, do qual as autoras fazem parte, é evidenciada uma procura constante por cursos de extensão tanto na área de avaliação quanto na área da Psicologia jurídica. Os profissionais buscam principalmente cursos que tratem dos instrumentos psicológicos, alegando pouco conhecimento ou total desconhecimento sobre os mesmos. No que diz respeito à área jurídica, a maioria dos alunos busca os cursos a fim de conhecer o assunto, justificando que não Ihes foi oferecida nenhuma disciplina referente ao tema ao longo da graduação.

Considerando o objetivo de investigar o conhecimento e a experiência de psicólogos que atuam na área do Direito de família, os resultados indicaram que a maioria dos participantes conhecia e tinha experiência a respeito da guarda compartilhada, da síndrome de alienação 
parental e de acusações de abuso sexual em casos de disputa de guarda. Contudo, $22,5 \%$ dos participantes desconhecia o termo síndrome de alienação parental. Conforme já apontado, o termo é recente na literatura nacional (Gardner, 1999), ainda que as características do fenômeno não o sejam. Mesmo assim, considerando que a amostra tenha sido composta apenas por profissionais que atuam no âmbito do Direito de família, esse é um percentual alto de desconhecimento do assunto. Literaturas científicas nacionais sobre o tema ainda são escassas, mas, na literatura internacional, é possível encontrar artigos e livros sobre o tópico em questão (Gardner, 1987, 1999, 2002). Ademais, associações de pais como o PaiLegal (www.pailegal.net) e a Associação de Pais e Mães Separados (APASE, www. apase.org.br) têm se encarregado de difundir amplamente e apoiar pais que passam pela situação da síndrome de alienação parental (Podevyn, 2001; Silva et. al, 2007). As páginas desses grupos na Internet disponibilizam textos interessantes que tratam da SAP e de outros assuntos que envolvem separação conjugal, portanto, é importante refletir acerca dessa desinformação por parte desses profissionais e buscar maneiras de preencher as lacunas deixadas pela escassa formação na área jurídica existente em nosso país.

Outro aspecto interessante a ser pontuado é que, dentre a extensa lista de assuntos que os participantes consideram exigir maior atualização, o assunto síndrome de alienação parental não foi citado. Talvez haja um descrédito por parte de alguns profissionais em relação a tal síndrome, no sentido de classificar como síndrome uma dinâmica já existente há anos entre os casais que se separam. Contudo, é preciso considerar a interface com a área jurídica, uma vez que muitos advogados já têm se utilizado dessa nomenclatura para a defesa de seus clientes (Fonseca, 2006). Esse fato exige que o psicólogo conheça e saiba como diagnosticar a síndrome de alienação parental, evitando incorrer em avaliações malsucedidas.
Um assunto que se encontra diretamente ligado à SAP são as falsas acusações de abuso sexual. Chamam a atenção os resultados apresentados na Tabela 3, em que o percentual de participantes da Região Sul que relatou não ter experiência com o assunto se apresenta mais elevado em comparação às demais Regiões do País. Esse dado suscita questões como a dificuldade de constatação das falsas acusações de abuso e a complexidade da avaliação psicológica que envolve esse tipo de situação. Sugere-se a realização de estudos qualitativos, de forma a investigar de modo mais detalhado as avaliações em situações de abuso sexual e sua possível relação com a SAP.

Os dados referentes à situação de disputa de guarda relacionada ao crescente número de genitores masculinos que pleiteiam a guarda dos filhos corroboram os dados históricos do surgimento da guarda compartilhada (Peres, 2002). A sociedade moderna busca cada vez mais romper a visão tradicional de que apenas a mãe é capaz de cuidar dos filhos. Existe o objetivo de que o pai também possa desempenhar as tarefas de cuidado dos filhos, através da guarda exclusiva ou da guarda compartilhada. Silva (2006) ressalta em sua obra que há alguns anos esses pedidos de guarda por parte do pai eram vistos como uma forma de desobrigar-se da responsabilidade de pagar pensão alimentícia ao filho, porém é crescente o número de pais que requerem a guarda dos filhos por uma questão de conscientização da importância da figura paterna no seu desenvolvimento.

No que tange à guarda compartilhada, os requisitos mencionados pelos participantes para que a mesma possa ser indicada corroboram os dados da literatura apresentados por Irving e Benjamin (1991) e Saposnek (1991). Os fatores considerados importantes para recomendar a guarda compartilhada, apresentados na Tabela 2, complementam tais requisitos. É possível concluir que o tipo de relacionamento entre os pais é fator decisivo para a recomendação da guarda compartilhada. Em havendo um bom relacionamento entre os ex-cônjuges, haverá 
maior flexibilidade e maturidade diante das decisões conjuntas que deverão tomar sobre a vida dos filhos. É importante considerar ainda a qualidade de relacionamento da criança com cada um dos pais, de forma que a guarda compartilhada privilegie a manutenção desses vínculos.

\section{Considerações finais}

Os assuntos apresentados e discutidos neste artigo permitiram contextualizar e atualizar os psicólogos que trabalham ou desejam trabalhar no âmbito do Direito de família. A revisão teórica é importante na medida em que pode apresentar aspectos históricos, conceituais e as repercussões dos assuntos abordados, permitindo uma compreensão da origem e desenvolvimento dos mesmos. O levantamento empírico, por sua vez, complementa a revisão teórica através da apresentação de dados referentes à realidade de psicólogos de diferentes Regiões do Brasil frente às demandas emergentes do Direito de família.

A necessidade apontada pelos participantes de buscar conhecimentos sobre abuso sexual, guarda de filhos, avaliação psicológica, preconceito de gênero e estudos interdisciplinares justifica a relevância deste estudo. Os resultados empíricos analisados possibilitaram relacionar os dados da realidade brasileira com aqueles evidenciados na literatura internacional. A discussão dos resultados revelou a necessidade de se abordar uma grande variedade de tópicos referentes à Psicologia jurídica. Esse fato implica a inclusão de disciplinas que tratem do assunto durante a formação acadêmica, tanto no nível de graduação quanto no de pós-graduação. Estudos que abordem temas como mediação e outros assuntos afins à área da Psicologia da família devem ser realizados, pois essa carência pôde ser evidenciada a partir dos resultados aqui apresentados.

Existem alguns pontos que merecem maior investigação e que não foram questionados neste estudo. Citam-se, por exemplo, as práticas em avaliação que envolvem acusações de abuso sexual e disputa de guarda e os critérios diagnósticos para a síndrome de alienação parental. É importante ressaltar também que, em razão de tratar-se de temas recentes na literatura, é necessário que pesquisas de levantamento como esta permitam maior expressão de idéias dos participantes. Assim, observou-se a necessidade de elaboração de maior número de questões abertas, a fim de colher informações mais consistentes.

Finalmente, observa-se a importância de o psicólogo que atua na área do Direito de família considerar em sua avaliação os vínculos afetivos que forem saudáveis ao desenvolvimento da criança. Portanto, sugere-se que pesquisas futuras investiguem a avaliação psicológica forense e as diversas áreas de intersecção com a mesma, buscando suprir as necessidades indicadas pelos participantes deste estudo.

Vivian de Medeiros Lago*

Mestre em Psicologia, Doutoranda em Psicologia pela Universidade Federal do Rio Grande do Sul (UFRGS)

Denise Ruschel Bandeira

Doutora em Psicologia, Professor Adjunto da Universidade Federal do Rio Grande do Sul (UFRGS)

E-mail: drbandei@terra.com.br

*Endereço para envio de correspondência:

Rua Ramiro Barcelos, 2.600/120 - Bairro Santana, Porto Alegre - RS - Brasil, CEP 90035-003

E-mail:vmlago@gmail.com

Recebido 28/01/2008 Reformulado 27/01/2009 Aprovado 02/02/2009 
Referências
Bauserman, R. (2002). Child adjustment in joint-custody versus sole-custody arrangements: A meta-analytic review. Journal of Family Psychology, 16, 91-102.

Benedek, E., \& Schetky, D. (1985). Allegations of sexual abuse in child custody and visitation disputes. In E. Benedek \& D. Schetky, Emerging issues in child psychiatry and the law (pp. 145-456). New York: Brunner/Mazel.

Bow, J. N., Quinnell, F. A., Zaroff, M., \& Assemany, A. (2002). Assessment of sexual abuse allegations in child custody cases. Professional Psychology: Research and Practice, 33, 566-575.

Brasil. (2003). Lei n 10.406/02. In Código civil. São Paulo: Saraiva.

Brasil. (n.d.). Projeto de Lei $n^{\circ}$ 6.350/02. Recuperado em novembro de 2007, de http://www2.camara.gov.br/ proposicoes

Calçada, A. (2005). Falsas acusações de abuso sexual: parâmetros iniciais para uma avaliação. In W. Grisard Filho, A. Calçada, E. L. Silva, L. M. T. Brito, P. P. O Ramos, E. R., Nazareth, \& R. B. C. Simão, Guarda compartilhada: aspectos psicológicos e jurídicos (pp. 123-144). Porto Alegre: Equilíbrio.

Calçada, A., Cavaggioni, A., \& Neri, L. (2001). Falsas acusações de abuso sexual: o outro lado da história. Rio de Janeiro: Produtor Editorial Independente.

Deed, M. L. (1991). Court-ordered child custody evaluations: Helping or victimizing vulnerable families. Psychoterapy: Theory, Research, Pratice, Training, 28(1), 76-84.

Dias, M. B. (2006). Síndrome da alienação parental, o que é isso? Jus Navigandi, 10, 1119. Recuperado em novembro de 2007, de http://jus2.uol.com.br/doutrina/texto.asp?id=8690

Flores, R. Z., \& Caminha, R. M. (1994). Violência sexual contra crianças e adolescentes: algumas sugestões para facilitar o diagnóstico correto. Revista de Psiquiatria do Rio Grande do Sul, 16, 158-167.

Fonseca, P. M. P. C. (2006). Síndrome de alienação parental. Pediatria São Paulo, 28(3), 162-168.

Gardner, R. A. (1987). The parental alienation syndrome and the differentiation between fabricated and genuine child sexual abuse. Cresskill, NJ: Creative Therapeutics.

Gardner, R. A. (1999). Differentiating between parental alienation syndrome and bona fide abuse-neglect. The American Journal of Family Therapy, 27, 97-107.

Gardner, R. A. (2002). Parental alienation syndrome vs. parental alienation: Which diagnosis should evaluators use in childcustody disputes? American Journal of Family Therapy, 30, 93-115.

Hutz, C. S., \& Bandeira, D. R. (2003). Avaliação psicológica no Brasil: situação atual e desafios para o futuro. In $\mathrm{O}$. $\mathrm{H}$. Yamamoto \& V. V. Gouveia (Orgs.), Construindo a psicologia brasileira: desafios da ciência e prática psicológica (pp. 261277). São Paulo: Casa do Psicólogo.

Instituto Brasileiro de Geografia e Estatística. (2005). Estatísticas do registro civil 2005. Recuperado em novembro de 2007, de http://www.ibge.gov.br/home/estatistica/populacao/ registrocivil/2005/default.shtm

Irving, H. H., \& Benjamin, M. (1991). Shared and sole-custody parents: A comparative analysis. In J. Folberg, Joint custody and shared parenting (pp. 114-131). New York: The Guilford Press.

Jacó-Vilela, A. M. (1999). Os primórdios da psicologia jurídica. In L. M. T. Brito, Temas de psicologia jurídica (pp. 11-17). Rio de Janeiro: Relume Dumará.

Kaplan, H. I., \& Sadock, B. J. (1990). Compêndio de psiquiatria (2a ed.). Porto Alegre: Artes Médicas.

Lago, V. M., \& Bandeira, D. R. (2008). As práticas em avaliação psicológica envolvendo disputa de guarda no Brasil. Avaliação Psicológica, 7(2), 223-234.

Lima, A. A. (2007). Psicologia jurídica: lugar de palavras ausentes. São Paulo: Evocati.

Major, J. A. (2000). Parents who have successfully fought parental alienation syndrome. Recuperado em dezembro de 2007, de http://www.livingmedia2000.com/pas.htm

McGleughlin, J., Meyer, S., \& Baker, J. (1999). Assessing sexual abuse allegations in divorce, custody, and visitation disputes. In R. M. Galatzer-Levy \& L. Kraus, The scientific basis of child custody decisions (pp. 357-388). New York: Wiley.

McGraw, J. M., \& Smith, H. A. (1992). Child sexual abuse allegations amidst divorce and custody proceedings: Fining the validation process. Journal of Child Sexual Abuse, 1, 49-62.

Motta, M. A. P. (2007). A síndrome da alienação parental. In E. L. Silva, M. Resende, M. A. P. Motta, T. Féres-Carneiro, M. L. C. S. Valente, \& R. B. C. Simão, Síndrome de alienação parental e a tirania do guardião (pp. 40-72). Porto Alegre: Equilíbrio.

Myers, J. E. B. (1992). Legal issues in child abuse and neglect. Thousand Oaks, CA: Sage.

Nygaard, M. L. C., Feix, L. F., \& Stein, L. M. (2006). Contribuições da psicologia cognitiva para a oitiva da testemunha: avaliando a eficácia da entrevista cognitiva. Revista Brasileira de Ciências Criminais, 61, 147-180.

Peres, L. F. L. (2002). Guarda compartilhada. Jus Navigandi, 7(60). Recuperado em novembro de 2007, de http://jus2.uol.com. br/doutrina/texto.asp?id=3533

Pisa, O., \& Stein, L. M. (2006). Entrevista forense de crianças: técnicas de inquirição e qualidade do testemunho. Revista da Ajuris, 23, 217-255

Podevyn, F. (2001). Síndrome de alienação parental. Recuperado em novembro de 2007, de http://www.apase.org.br/94001sindrome.htm

Rovinski, S. L. (2004). Fundamentos da perícia psicológica forense. São Paulo: Vetor.

Saposnek, D. T. (1991). A guide to decisions about joint custody: The needs of children of divorce. In J. Folberg, Joint custody and shared parenting (pp. 29-40). New York: The Guilford Press.

Silva, D. M. P. (2006). Psicologia jurídica no processo civil brasileiro. São Paulo: Casa do Psicólogo.

Silva, E. L. (2005). Guarda de filhos: aspectos psicológicos. In W. Grisard Filho, A. Calçada, E. L. Silva, L. M. T. Brito, P. P. O Ramos, E. R., Nazareth, \& R. B. C. Simão, Guarda compartilhada: aspectos psicológicos e jurídicos (pp. 13-31). Porto Alegre: Equilíbrio.

Silva, E. L., Resende, M., Motta, M. A. P., Féres-Carneiro, T., Valente, M. L. C. S., \& Simão, R. B. C. (2007), Síndrome de alienação parental e a tirania do guardião. Porto Alegre: Equilíbrio.

Simão, R. B. C. (2007). Soluções judiciais concretas contra a perniciosa prática da alienação parental. In E. L. Silva, M. Resende, M. A. P. Motta, T. Féres-Carneiro, M. L. C. S. Valente, \& R. B. C. Simão, Síndrome de alienação parental e a tirania do guardião (pp.15-28). Porto Alegre: Equilíbrio.

Stein, L. M. (2000). Falsas memórias em depoimentos de testemunhas. In Universidade Presbiteriana Mackenzie (Org.), Anais do III Congresso Ibero-americano de Psicologia Jurídica (pp. 213-216). São Paulo.

Stein, L. M., \& Nygaard, M. L. (2003). A memória em julgamento: uma análise cognitiva dos depoimentos testemunhais. Revista Brasileira de Ciências Criminais, 11(43), 151-164.

Thoennes, N., \& Tjaden, P. G. (1990). The extent, nature, and validity of sexual abuse allegations in custody/visitation disputes. Child Abuse and Neglect, 14, 151-163.

Tonetto, L. M., Kalil, L. L., Melo, W. V., Schneider, D. G., \& Stein, L. M. (2006). O papel das heurísticas no julgamento e tomada de decisão sob incerteza. Estudos de Psicologia (Campinas), 23(2), 181-189.

Trindade, J. (2004). Manual de psicologia jurídica para operadores do direito. Porto Alegre: Livraria do Advogado Editora.

Wakefield, H., \& Underwager, R. (1991). Sexual abuse allegations in divorce and custody disputes. Behavioral Sciences and the Law, 9, 451-468. 